\title{
Does increased information about reproductive potential result in better prediction of recruitment?
}

\author{
M. Joanne Morgan, Alfonso Perez-Rodriguez, and Fran Saborido-Rey
}

\begin{abstract}
The relationship between stock size and recruitment is an essential element in the understanding of the productivity of a population. However, predicting the number of recruits produced by a population has proven to be a difficult challenge. This may in part be a result of poor estimation of reproductive potential (RP). We determined if including increased information on reproductive biology in indices of RP results in better predictions of recruitment. We investigated some of the conditions that lead to better (or worse) recruitment prediction when more biologically complex indices of RP are used. Data from four populations in the Northwest Atlantic were examined: southern Grand Bank (NAFO Division 3NO) cod (Gadus morhua), Flemish Cap (NAFO Division 3M) cod, Newfoundland (NAFO Division 3LNO) American plaice (Hippoglossoides platessoides), and Greenland halibut (Reinhardtius hippoglossoides) (NAFO Subarea 2 + Division 3KLMNO). Stock-recruit models paired with complex indices of RP gave a better estimate of recruitment in slightly more than half of the tests conducted. When there were larger trends in the reproductive biology (maturity at age, sex ratio and egg production), more complex indices of RP were more likely to provide a better estimate of recruitment.
\end{abstract}

Résumé : La relation entre la taille d'un stock et le recrutement est un élément essentiel pour la compréhension de la productivité d'une population. Cependant, la prédiction du nombre de recrues produites par la population s'est avérée être un défi difficile. Ce peut en partie être le résultat d'une mauvaise estimation du potentiel reproductif (RP). Nous avons déterminé si l'addition d'information supplémentaire sur la biologie de la reproduction dans les indices de RP produit de meilleures prédictions du recrutement. Nous avons étudié certaines des conditions qui entraînent une meilleure (ou moins bonne) prédiction du recrutement lorsque des indices plus biologiquement complexes de RP sont utilisés. Nous avons examiné les données provenant de quatre populations du nord-ouest de l'Atlantique, les morues (Gadus morhua) du Grand Banc sud (NAFO Division 3NO), les morues de Flemish Cap (NAFO Division 3M), les plies canadiennes (Hippoglossoides platessoides) de Terre-Neuve (NAFO Division 3LNO) et les flétans du Groenland (Reinhardtius hippoglossoides) (NAFO sousrégion $2+$ Division 3KLMNO). Les modèles stocks-recrues appariés à des indices complexes de PR donnent une meilleure estimation du recrutement dans un peu plus de la moitié des tests. Lorsqu'il y a des tendances plus marquées dans la biologie de la reproduction (maturité en fonction de l'âge, proportion des sexes, production des œufs), les indices plus complexes de PR sont plus susceptibles de fournir une meilleure estimation du recrutement.

[Traduit par la Rédaction]

\section{Introduction}

Predicting the number of recruits produced by a population has proven to be a difficult challenge in fisheries science. Yet the relationship between stock size and recruitment is an essential element in the understanding of the productivity of a population (Hilborn and Walters 1992; Needle 2002). The stock-recruit (S-R) relationship will determine the level of fishing mortality a population can sustain. As a result, S-R relationships form the basis for the setting of many reference

Received 25 June 2010. Accepted 24 March 2011. Published at www.nrcresearchpress.com/cjfas on .

J21893

Paper handled by Associate Editor C. Tara Marshall.

M.J. Morgan. Fisheries and Oceans Canada, P.O. Box 5667, St. John's, NL A1C 5X1, Canada.

A. Perez-Rodriguez and F. Saborido-Rey. Institute of Marine Research, CSIC, Vigo, Spain.

Corresponding author: M. Joanne Morgan (e-mail: Joanne. Morgan@dfo-mpo.gc.ca). points in fisheries management (Sissenwine and Shepherd 1987; Mace 1994).

The reproductive potential (RP) of a population is its potential to produce recruitment and is determined by a combination of factors including maturation, sex ratio, and fecundity (Trippel 1999). The actual recruitment that arises from this RP is greatly influenced by environmental impacts on egg and larval survival (Shepherd et al. 1984; Cushing 1996). However, the underlying RP also plays a role (Myers and Barrowman 1996). In fact, the impact of poor environmental conditions on recruitment may be exacerbated at low levels of RP (Brander 2005). The importance of RP means that difficulty in estimating recruitment may in part be a result of poor estimation of RP. Error in the measurement of $\mathrm{RP}$ or failure to use an index of RP that adequately reflects a population's actual RP can obscure any S-R relationship (Walters and Ludwig 1981; Cadigan 2009). RP is often expressed as a metric that does not account for variation in maturation and sex ratio. Changes in fecundity are rarely incorporated into indices of RP (Morgan 2008; Marshall 2009). However, it is clear that populations can exhibit large 
variation, and more importantly trends over time, in these biological characteristics (Jørgensen 1990; Jakobsen and Ajiad 1999; Rideout and Morgan 2007). It is also clear that using more complex indices of RP that account for this variation in reproductive biology can result in an altered perception of population productivity and hence sustainable levels of fishing (Scott et al. 2006; Marshall et al. 2003; Morgan et al. 2009).

Since biological factors incorporated into more complex indices of RP are themselves estimated with error, their use may simply add more error to the estimate of RP. Therefore, it is uncertain whether they will result in an improved S-R relationship or ability to predict recruitment. In addition, environmental influences on offspring survival may make the detection of RP affects difficult (Brunel 2010). Only a few studies have examined whether more complex indices of RP improve the ability to predict recruitment, and the results have been equivocal (Marteinsdottir and Thorarinsson 1998; Kraus et al. 2002; Marshall et al. 2006). Given the importance of the S-R relationship to our understanding of population productivity, an increase in error in recruitment prediction as a result of using poorly estimated biological characteristics in our construction of RP would be undesirable (Morgan 2008; Marshall 2009; Brunel 2010).

The purpose of this study was to determine if more complex indicators of RP result in better predictions of recruitment. We also investigate some of the conditions that lead to better (or worse) recruitment prediction when more biologically complex indicators of RP are used. We examine four indices of RP in four populations of groundfish in the Northwest Atlantic.

\section{Materials and methods}

Data from four populations in the Northwest Atlantic off the east coast of Canada were examined: southern Grand Bank cod (Gadus morhua) in Northwest Atlantic Fisheries Organization (NAFO) Division 3NO, Flemish Cap cod in NAFO Division 3M, Newfoundland American plaice (Hippoglossoides platessoides) in NAFO Division 3LNO, and Greenland halibut (Reinhardtius hippoglossoides) in NAFO Subarea $2+$ Division 3KLMNO. Population numbers at age and masses at age were taken from recent stock assessments of these populations: southern Grand Bank cod in Morgan et al. (2007); Greenland halibut in Healey and Mahé (2008); American plaice in Dwyer et al. (2009); Flemish Cap cod in González-Troncoso and Fernández (2009). All population models used a plus group except for southern Grand Bank cod. The age range in the assessment for southern Grand Bank cod was 2-12, for Flemish Cap cod 1-8+, for 3LNO American plaice 5-15+, and for Greenland halibut 1-14+.

Data on maturity, sex ratio, and fecundity were collected from research vessel bottom trawl surveys catches. The American plaice and southern Grand Bank cod data were collected during Canadian spring surveys mainly from 1975 to 2008, although some data from as early as 1965 were included. Maturity stage was determined macroscopically, which is generally easy at this time of the year. Fecundity data were available from only a few years (see below). For both of these populations, the surveys covered their whole distribution. For Greenland halibut, Canadian research vessel bottom trawl surveys were conducted in the fall from 1978 to 2007. Survey data from Divisions 2 J and $3 \mathrm{~K}$ only were used, as these areas had the most consistent coverage of the deep water areas inhabited by Greenland halibut. Maturities were determined macroscopically, which is generally considered accurate, given that gonads have begun to develop at this time of year for the next spawning season. The bottom trawl survey does not have good catchability of large fish. In addition, starting in the early 1990s the frequency of older and larger fish declined substantially, meaning that there are few data from adults, probably increasing the variability in the estimates of maturity at age, and possibly sex ratio. A single fecundity relationship for Greenland halibut was taken from the literature (Bowering 1980). Flemish cap cod survey data were available from Canada (1978-1985, February) and Spain (1988-2008, July). In both cases the entire distribution of the population was surveyed. The Canadian survey relied on macroscopic determination of maturity stage, while the Spanish survey used histology to determine maturity stage. The latter is generally more accurate, particularly in the summer, but sample size is low. In autumn 1996, a survey of the Flemish Cap was conducted by Canada that used the macroscopic method for staging maturity. This allowed a comparison with the Spanish survey conducted in July of 1997. Estimates of length at $50 \%$ maturity were similar from both surveys $($ Spanish $=45.8 \mathrm{~cm}$, Canadian $=46.2 \mathrm{~cm}$ ), indicating that changes in maturity over time are real and not a result of the change in methodology. For Flemish Cap cod, a single fecundity length relationship was taken from Rideout and Morgan (2009).

Proportion mature at age was estimated by cohort using generalized linear models with a logit link function and binomial error. Age was treated as a continuous variable, since in general it is not possible for there to be a lower proportion of adults at age $a+1$ than at age $a$ (Morgan and Colbourne 1999). For cohorts where there was no significant model fit to the data, the average of estimates from adjacent cohorts or of the three closest cohorts were used. All ages were used in the fitting. Sample sizes per cohort were generally large, ranging from 87 to 835 for southern Grand Bank cod, from 105 to 3644 for Flemish Cap cod, from 272 to 1908 for American plaice, and from 219 to 1356 for Greenland halibut.

Sex ratio (proportion female) at age was also estimated using generalized linear models with a logit link function and binomial error. These models had the form sex ratio $=$ age + cohort, where age and cohort were both class variables. In this case age was treated as a class variable, since there is no a priori reason to believe that sex ratio would change continuously across age (Morgan and Brattey 2005). Only ages for a cohort with at least five observations (10 for southern Grand Bank cod) were used in the fitting. Sample sizes for a cohort ranged from 119 to 1270 for southern Grand Bank cod, from 40 to 7298 for Flemish Cap cod, 1041 to 2852 for American plaice, and from 753 to 1527 for Greenland halibut. Similar to proportion mature at age, for cohorts where there was no significant fit to the data, averaging was used to produce the sex ratio. For Greenland halibut, a single model did not seem to adequately describe the changes in sex ratio (based on examination of patterns in the residuals), and so two separate models were fit: one using the 19691980 cohorts and the second using the 1981-1999 cohorts. 
Far fewer data were available for the estimation of fecundity. For Flemish Cap cod and Greenland halibut, only single fecundity length relationships were available, which were applied to mean length at age to produce egg production at age. Yearly relationships of fecundity and mass were available for southern Grand Bank cod in 1990, 1993, 1994, 1996, 19982003 and for American plaice in 1993-1998 and 2005. These were applied to mean mass at age to produce fecundity at age. For southern Grand Bank cod and American plaice in years for which no relationship was available, a single fecundity mass relationship using all fecundity data was used. The length at age (for Flemish Cap cod and Greenland halibut) or mass at age (for Grand Bank cod and American plaice) used were the beginning of the year estimates from the assessment and should be similar to spawning time for spring spawning fish. However, length and mass at age were for sexes combined and so could deviate from true female mass or length. Fecundity is determined mostly by size (length and mass), and so age was not included in the modeling (Lambert et al. 2003).

To examine some of the potential reasons for any differences between the populations in the ability of different indices of RP to predict recruitment, we examined trends in maturity at age, sex ratio, and fecundity. We used a metric for each that reflected changes over time. For maturity at age this was age at $50 \%$ maturity. For sex ratio it was the parameter estimate for the cohort effect. For fecundity we summed, for each year, the number of eggs produced by one fish at each age. We then standardized this by dividing the egg production for each year by the average across all years for the population.

Four indices of RP were calculated using the above data. The first estimate of RP (+BIO) did not incorporate fecundity and assumed no change in the maturity schedule of the fish, or in the sex ratio, and that all fish older than a particular age are mature.

$$
+\mathrm{BIO}=\sum_{a=i}^{j} N_{a y} M_{a y}
$$

where $N_{a y}$ is the population number at age $a$ in year $y, M_{a y}$ the mass at age $a$ in year $y, j$ is the maximum age in the sequential population analyses for the population, and $i$ is 6,5 , 9, and 10 (the age at which all fish are assumed to be mature) for southern Grand Bank cod, Flemish Cap cod, American plaice, and Greenland halibut, respectively. This index is simply the sum of the biomass of all fish greater than a given age.

The second estimate, spawning stock biomass (SSB), incorporates the estimated proportion mature at age for each cohort, that is, variable rather than constant maturity at age.

$$
\mathrm{SSB}=\sum_{a=i}^{j} N_{a y} M_{a y} \mathrm{PM}_{a y}
$$

where $i$ is the first age in the virtual population analysis (VPA) for the stock, $\mathrm{PM}_{a y}$ is the proportion mature at age $a$ in year $y$.

In the third estimate of RP, we applied the sex ratios estimated along with the variable estimates of proportion mature at age to obtain a female-only spawning stock biomass (FSB):

$$
\mathrm{FSB}=\sum_{a=i}^{j} N_{a y} M_{a y} \mathrm{PM}_{a y} \mathrm{SR}_{a y}
$$

where $\mathrm{SR}_{a y}$ is the sex ratio (i.e., proportion female) at age $a$ in year $y$, and the other symbols are as defined above.

The fourth estimate of RP incorporated estimates of fecundity at age and is an estimate of total egg production (TEP).

$$
\mathrm{TEP}=\sum_{a=i}^{j} N_{a y} \mathrm{PM}_{a y} \mathrm{SR}_{a y} E_{a y}
$$

where $E_{a y}$ is the number of eggs produced (i.e., potential fecundity) per female at age $a$ in year $y$, and the other symbols are as defined above.

To examine the differences in indices of RP, we standardized each index to its mean and variance. We then plotted each index of RP for a population on the same plot to see how they differed from one another.

Three S-R models were fit to each index of RP. These were both parametric (Beverton-Holt and Ricker) and nonparametric (generalized additive models). The first two were based on S-R theory (Beverton and Holt 1957; Ricker 1954) and assume a particular functional relationship. Generalized additive models are also used to model S-R relationships (Cardinale and Arrhenius 2000; Lee et al. 2009; Brunel 2010) but do not impose a functional form. For each S-R model, the RP that gave the best predictor of recruitment was determined to see if predictability was improved for a given S-R model by using more complex indices of RP. Different indices of RP may not just alter the fit of a particular $\mathrm{S}-\mathrm{R}$ model but may actually change the shape of the S-R relationship from one best described by one model to one best described by a different model. Poor ability to predict recruitment could be due to inappropriate model choice rather than a real change in predictive ability. The issue of potential bias of using a single S-R model is accounted for by examining three different S-R models. The combination of S-R model and RP index giving the best prediction of recruitment was determined.

There were two tests of the ability to predict recruitment that were similar to the methods used by Lee et al. (2009). The first was the ability to predict $10 \%$ of the data that were selected at random and removed and the model then fit without these data. This first procedure was repeated 100 times for each S-R model for each index of RP for each population. In six cases out of 48 (four stocks $\times$ four indices of RP $\times$ three S-R models), there were problems with convergence and multiple runs were conducted to achieve 100 successful model fits. Results were accumulated from each run until 100 were complete. The second test was the ability to predict the most recent $10 \%$ of the data when these data were not used in the model fitting. Stock assessments are often tasked with examining sustainable fishing levels in the short to medium term. If recent recruitment levels are likely to be indicative of recruitment in the near future, then the ability to predict recent values should not be compromised. An additional reason for this second test is that leaving out the most recent data is a technique often used in evaluating the ability to predict (Lee et al. 2009). 
Fig. 1. Age at 50\% maturity estimated by cohort for each of the study populations. southern Grand Bank cod, circles; Flemish Cap cod, triangles; American plaice, squares; Greenland halibut, diamonds.

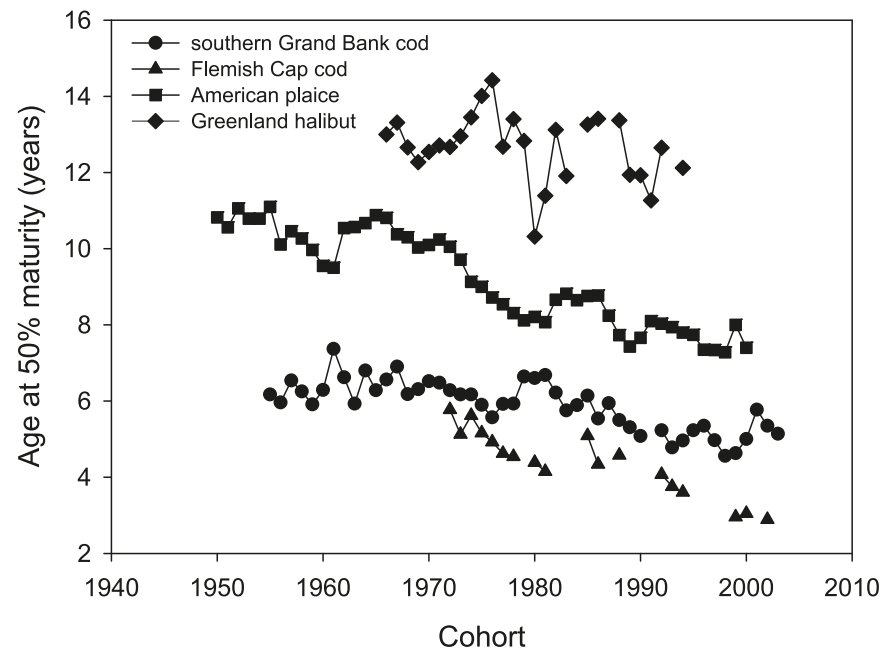

In both cases the measure of predictive ability was the mean absolute error (MAE), where

$$
\text { MAE }=\frac{\sum_{i=1}^{n}\left|Y_{i}-\widehat{Y}\right|}{n}
$$

that is, the average of the absolute difference between the observed and predicted recruitments. For each of these three tests for a population, we found the S-R model with the lowest MAE for each RP and then for each test the RP with the lowest MAE.

\section{Results}

All of the populations exhibited substantial variation in age at $50 \%$ maturity, with age at maturity being lower for more recent cohorts (Fig. 1). There was a clear declining trend throughout the time series for southern Grand Bank cod, Flemish Cap cod, and American plaice. Linear regressions showed that the decline was significant $(p<0.0001)$ and steepest for Flemish Cap cod and American plaice, with slopes of -0.08 for each population. The decline was less for southern Grand Bank cod at -0.04 , but still significant $(p<$ $0.0001)$. For Greenland halibut the slope was -0.03 and the regression was not significant.

The effect of cohort on sex ratio was also highly variable over time for most stocks (Fig. 2). The clearest trends were again for Flemish Cap cod and American plaice, and the least variation was found for Greenland halibut. The greatest range in parameter estimates was for American plaice, but there was no consistent trend over the entire time series for that population. There was a decline to the early 1980s followed by a large increase to 1987 and then a general decline. For Flemish Cap cod, there was an increasing trend (indicating an increasing proportion female) across the whole time series.

Greenland halibut also showed the least variation in standardized egg production (Fig. 3). The largest variation was found in Flemish Cap cod, which had an increasing trend
Fig. 2. The parameter estimate for the effect of cohort on sex ratio (proportion female) for each of the study populations: $(a)$ southern Grand Bank cod, (b) Flemish Cap cod, $(c)$ American plaice, and

(d) Greenland halibut.
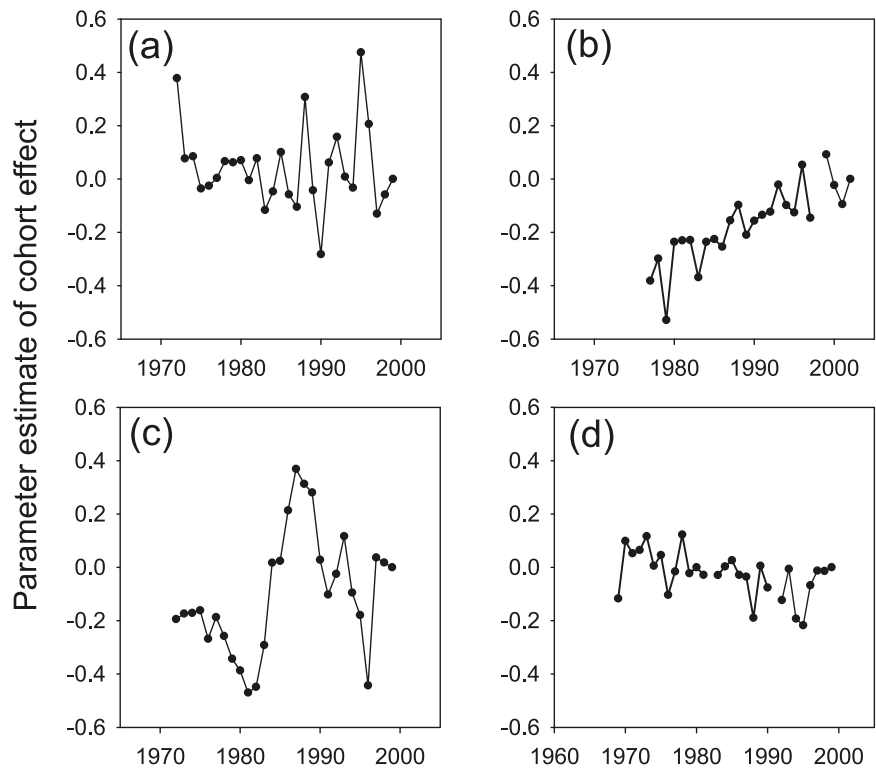

Cohort

Fig. 3. The standardized egg production for each year for each of the study populations: $(a)$ southern Grand Bank cod, $(b)$ Flemish Cap cod, (c) American plaice, and (d) Greenland halibut. For each year, the number of eggs produced by one fish at each age for the age range used in the indices of reproductive potential (RP) was summed. This metric was then standardized by dividing the egg production for each year by the average across all years for the population.
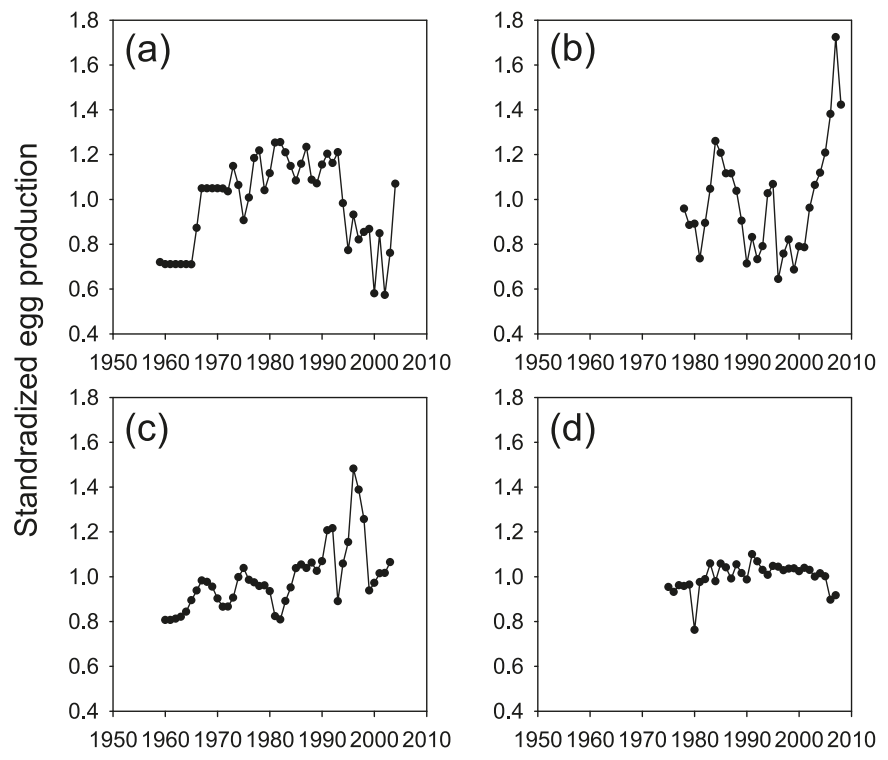

Year

from 1999 to 2008 over which time egg production more than doubled. American plaice had a general increasing trend in egg production up to 1996, followed by a large decline. Southern Grand Bank cod had higher egg production from 
Fig. 4. The standardized indices of reproductive potential (RP) for each year for each of the study populations: (a) southern Grand Bank cod, (b) Flemish Cap cod, $(c)$ American plaice, and $(d)$ Greenland halibut. Each index was standardized by its mean and variance. +BIO, solid line; spawning stock biomass (SSB), short dashed line; female spawning stock biomass (FSB), dotted line; total egg production (TEP), dashdot-dashed line.
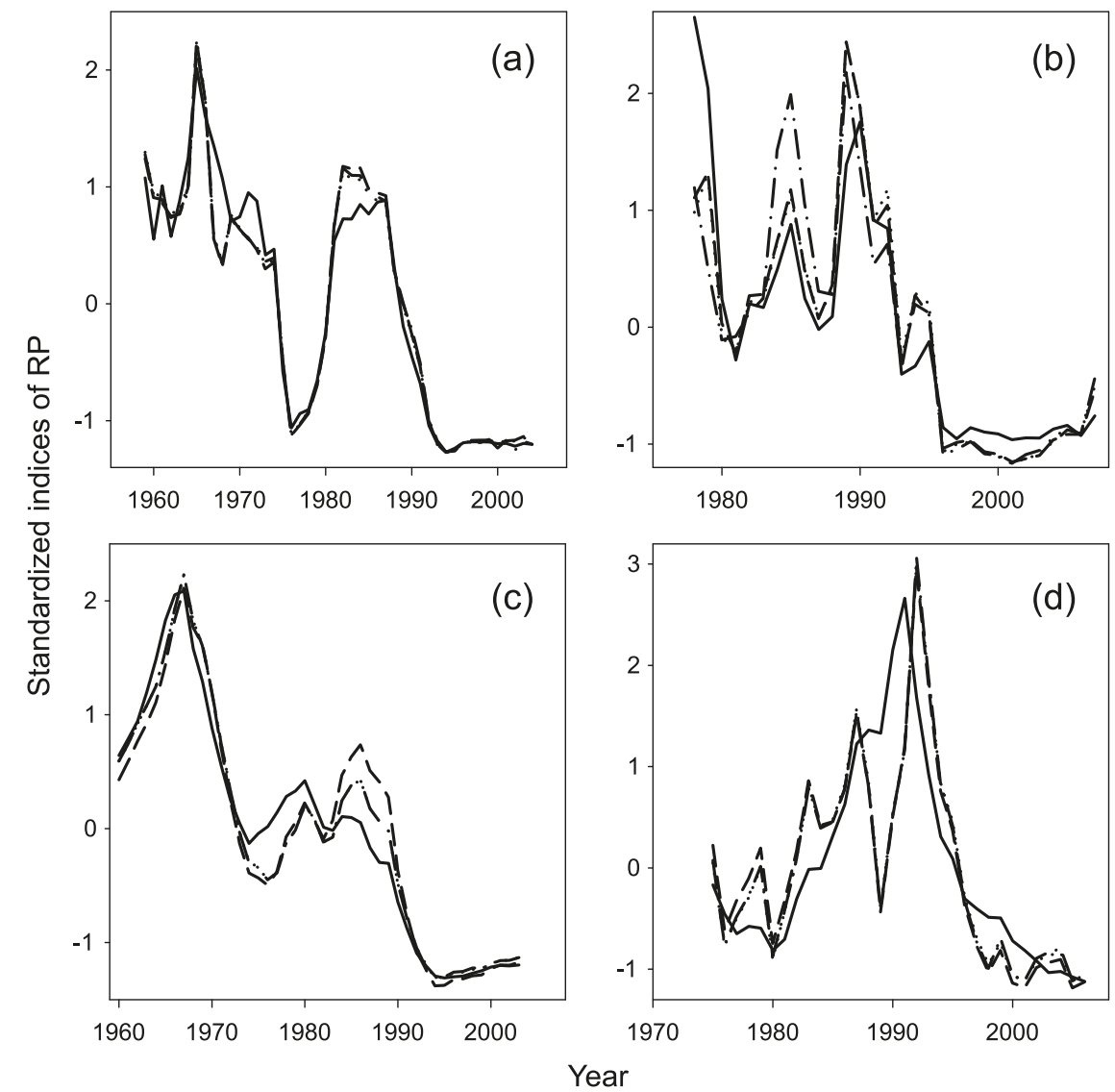

the late 1960 s to the early 1990 s, but there were few trends over the time period.

The more complex indices of RP differed from $+\mathrm{BIO}$ for all populations (Fig. 4). They were generally more similar to one another than to $+\mathrm{BIO}$. The relative position of the indices varied over time for all populations, but the pattern was unique to each population. For Greenland halibut, the more complex indices of RP were generally above standardized $+\mathrm{BIO}$ in the first part of the time series and lower in the second part of the time series. For Flemish Cap cod, the more complex indices of RP were above +BIO from 1980 to 1995. All indices of RP show a steep increase in the most recent years, but the increase is much greater for the more complex indices of RP. For American plaice, there were three shifts in the position of standardized $+\mathrm{BIO}$ relative to all other indices of RP. Since the early 1990s, it has been below TEP and FSB but above SSB. In southern Grand Bank cod, there have also been several shifts in the position of standardized $+\mathrm{BIO}$ relative to other indices of RP, but since the early 1990s they have all been quite similar.

When $10 \%$ of the data were left out at random 100 times and predicted from the model fit to the remainder of the data, two of the four populations had S-R models combined with more complex indices of RP that gave the lowest MAE (Table 1). These were southern Grand Bank cod for which the lowest S-R-RP index combination was Beverton-Holt

with TEP and for Flemish Cap cod Beverton-Holt with FSB. However, the Beverton-Holt fit for southern Grand Bank cod to TEP failed to converge in 17 of the 100 model runs. The best predictor for this stock that did not have convergence problems was the Ricker model fit to SSB. For southern Grand Bank and Flemish Cap cod, more complex indices of RP were also the best predictors for each of the three S-R models, although which index of RP had the lowest MAE was not the same for all models. For both American plaice and Greenland halibut, the $+\mathrm{BIO}$ index of RP gave the lowest MAE. This was the case regardless of the S-R model used.

When trying to predict the most recent $10 \%$ of the observed data, the $+\mathrm{BIO}$ RP was the best predictor for only Greenland halibut (Table 2). For the other three populations, an S-R model paired with a more complex index of RP predicted the most recent observations better: TEP for southern Grand Bank cod, FSB for Flemish Cap cod, and SSB for American plaice. There was some variation in which index of RP had the lowest MAE for each S-R model (except for American plaice, for which SSB had the lowest MAE for all three models). However, for 8 of 12 population S-R model combinations, a more complex index of RP had the lowest MAE.

\section{Discussion}

One of the reasons for attempting to produce more biologically realistic indices of RP is the belief that this will lead to a

\section{PROOF/ÉPREUVE}


Table 1. Mean absolute error (MAE) for each index of reproductive potential (RP) for model predictions of $10 \%$ of observed recruitments removed at random, 100 times.

\begin{tabular}{lcccc}
\hline & + BIO & SSB & FSB & TEP \\
\hline Southern Grand Bank cod & & & \\
Beverton-Holt & 32.68 & 32.87 & 32.17 & $\mathbf{3 0 . 7 9} *$ \\
Ricker & 33.14 & $\mathbf{3 2 . 2 5}$ & 34.60 & 35.00 \\
GAM & 36.24 & 36.89 & 38.20 & $\mathbf{3 6 . 2 2}$ \\
& & & & \\
Flemish Cap cod & & & & \\
Beverton-Holt & 18.02 & 16.08 & $\mathbf{1 5 . 0 4} *$ & 16.12 \\
Ricker & 17.20 & 19.62 & $\mathbf{1 6 . 7 2}$ & 18.37 \\
GAM & 18.92 & 21.96 & 24.02 & $\mathbf{1 8 . 5 7}$ \\
& & & & \\
American plaice & & & & \\
Beverton-Holt & $\mathbf{4 2 . 1 2}$ & 48.42 & 45.37 & 46.77 \\
Ricker & $\mathbf{3 7 . 9 3}$ & 49.15 & 42.49 & 47.73 \\
GAM & $\mathbf{3 6 . 4 3} *$ & 50.68 & 48.80 & 45.54 \\
& & & & \\
Greenland halibut & & & & \\
Beverton-Holt & $\mathbf{2 5 . 2 9}$ & 28.19 & 29.58 & 27.50 \\
Ricker & $\mathbf{2 0 . 0 4}$ & 25.75 & 24.12 & 23.32 \\
GAM & $\mathbf{1 6 . 8 7} *$ & 29.10 & 26.14 & 26.03 \\
\hline
\end{tabular}

Note: For +BIO RP, all fish 6+ for southern Grand Bank cod, 5+ for Flemish Cap cod, 9+ for American plaice, and 10+ for Greenland halibut are considered to be mature. The other indices of RP are spawning stock biomass (SSB), female spawning stock biomass (FSB), and total egg production (TEP). Bool font indicates the RP giving the lowest MAE for each stock-recruitment (S-R) model. For each population, an asterisk $(*)$ indicates the RP index - S-R model combination giving the lowest MAE. GAM, generalized additive model.

better understanding of population productivity and better prediction of recruitment (Morgan 2008; Marshall 2009). To date, studies have found some examples where S-R relationships were improved and some where they were not (Marteinsdottir and Thorarinsson 1998; Murawski et al. 2001; Marshall et al. 2006). The results of this study were similar with slightly more than half of the tests showing that S-R models paired with more complex indices of RP did better in the prediction of recruitment than using indices of RP that did not account for variation in reproductive biology.

Populations with the greatest trends in maturity, sex ratio, and egg production were the ones where the best predictor of recruitment tended to come from more complex indices of RP. These trends in reproductive biology led to deviation of the more complex indices of RP from $+\mathrm{BIO}$ and to a lesser extent from each other. For the population with the greatest trends, Flemish Cap cod, more complex indices of RP were always the better predictors of recruitment. This feature of trends in variation in reproductive biology is likely to be an important factor leading to the need for more complex indices of RP. These trends make indices of RP that do not take variation in reproductive biology into account less reflective of the true RP of the population. In essence it increases the error with which these simple indices of RP measure true RP. This will lead to an obscuring of the relationship between stock and recruit (Walters and Ludwig 1981; Cadigan 2009).

For Greenland halibut, using the simplest index of RP (10+ biomass) resulted in the best predictor of recruitment in all tests. This population showed the least trend in maturity,
Table 2. Mean absolute error (MAE) for model predictions of the most recent $10 \%$ of observed recruitments for each index of reproductive potential (RP).

\begin{tabular}{lrrrl}
\hline & + BIO & SSB & FSB & TEP \\
\hline Southern Grand Bank cod & & & \\
Beverton Holt & 1.33 & 3.22 & 14.83 & $\mathbf{1 . 2 5}^{*}$ \\
Ricker & $\mathbf{1 . 3 3}$ & 2.49 & 2.38 & 1.83 \\
GAM & 2.31 & 6.52 & 6.45 & $\mathbf{1 . 9 8}$ \\
& & & & \\
Flemish Cap cod & & & & \\
Beverton Holt & 9.72 & 8.99 & $\mathbf{8 . 8 2}$ & 8.89 \\
Ricker & 9.77 & 8.97 & 8.82 & $\mathbf{8 . 7 6}$ \\
GAM & 9.92 & 9.08 & 8.85 & $\mathbf{8 . 8 2}$
\end{tabular}

American plaice

$\begin{array}{lllll}\text { Beverton Holt } & 31.22 & \mathbf{2 8 . 7 1} * & 29.48 & 29.77 \\ \text { Ricker } & 33.08 & \mathbf{2 9 . 0 8} & 30.17 & 30.37 \\ \text { GAM } & 33.83 & \mathbf{3 0 . 9 8} & 31.64 & 31.78\end{array}$

Greenland halibut

$\begin{array}{lllll}\text { Beverton Holt } & 33.53 & \mathbf{2 1 . 6 2} & 21.85 & 39.18 \\ \text { Ricker } & 24.19 & \mathbf{2 4 . 0 7} & 24.63 & 25.50 \\ \text { GAM } & \mathbf{1 6 . 9 6 *}^{*} & 41.43 & 42.43 & 43.04\end{array}$

Note: For +BIO RP, all fish 6+ for southern Grand Bank cod, 5+ for Flemish Cap cod, 9+ for American plaice, and 10+ for Greenland halibut are considered to be mature. The other indices of RP are spawning stock biomass (SSB), female spawning stock biomass (FSB), and total egg production (TEP). Bold font indicates the RP giving the lowest MAE for each stock-recruitment (S-R) model. For each population, an asterisk (*) indicates the RP index $-\mathrm{S}-\mathrm{R}$ model combination giving the lowest MAE is shaded. GAM, generalized additive model.

sex ratio, and fecundity, leading to little trend in the deviation of the constant RP from true RP. The biological factors will always be measured with error, and if there is little variation and (or) trend, incorporating these factors simply adds to the error in the measure of RP rather than capturing any real shift in the true RP of the population. Reducing errors in the measurement and estimation of biological factors may improve the estimation of RP. In the case of Greenland halibut, there is an additional reason why incorporating more biology into the indices of RP did not result in an improved prediction of recruitment. The assessment of this population only estimates numbers at age to age 13 with a plus group at age 14 (Healey and Mahé 2008). Age at $50 \%$ maturity in this population is currently age 12 . This means that most of the mature biomass is in the plus group. Indices of RP incorporating the measures of reproductive biology will only be minimally affected by any changes in reproductive investment, as most of the change will be "hidden" in the plus group.

Data on the biological factors determining RP were incomplete for all of these populations. None had a complete time series of fecundity so that fecundity in most (or all) years was calculated by using the fecundity-length or fecundity-mass relationship from another year. Changes in fecundity, therefore, were mostly a reflection of changes in growth. In effect, a proxy for fecundity was constructed for those years. If the proxy does not have a strong relationship with fecundity, or if that relationship changes over time, it will not likely lead to an improvement in the index of RP (De Oliveira et al. 2006). 
There is also error in estimates of sex ratio and maturity at age in all populations. For example, for Greenland halibut, estimates of maturity and sex ratio at age were complicated by the low catchability of older fish in the survey. For Flemish Cap cod, sample size was low for the estimation of maturity at age for recent cohorts. Despite these issues, in just over half of the tests more complex indices of RP gave a better estimate of recruitment. For populations where complex indices of RP gave better predictions of recruitment, the improvement was often small (small differences in MAE), but there was no sign of deterioration in the ability to predict recruitment. The added biological realism did not come at a price of predictive ability. If better time series of biological factors could be constructed, our ability to predict recruitment may improve further.

The factors required to build more complex indices of RP can themselves provide insight into changes in population productivity. Increased mortality can lead to changes in maturity, fecundity, and sex ratio (Jakobsen and Ajiad 1999; Yoneda and Wright 2004; Olsen et al. 2004). Changes in population abundance can result in density-dependent responses in maturation and fecundity (Rijnsdorp 1993; 1994). Even for those populations where the incorporation of these reproductive characteristics does not now improve our prediction of recruitment, it is important to continue to monitor these factors and to try to improve our understanding of the underlying causes of variation in them.

The index of RP that provides the best prediction of recruitment will be stock specific as seen in this study. It will depend on the amount of temporal variation in reproductive characteristics and on how well these are estimated. It might also change over time as better information over a longer time period is collected. Trend in this variation is more likely to make more complex indices of RP better predictors of recruitment. We should continue to test whether adding biological complexity results in better predictions of recruitment for more populations and for those populations already examined.

\section{Acknowledgements}

We thank the many people involved in the collection of these data. We thank J. Brattey, K. Dwyer, P. Pepin, and two anonymous reviewers for valuable comments on an earlier version of this manuscript. This paper is a product of the NAFO Working Group on Reproductive Potential and the EU COST Action FA0601 Fish Reproduction and Fisheries (FRESH).

\section{References}

Beverton, R.J.H., and Holt, S.J. 1957. On the dynamics of exploited fish populations. Ministry of Agriculture, Fisheries and Food, London, UK.

Bowering, W.R. 1980. Fecundity of Greenland halibut, Reinhardtius hippoglossoides (Walbaum), from southern Labrador and southeastern Gulf of St. Lawrence. J. Northwest Atl. Fish. Sci. 1: 39-43. doi:10.2960/J.v1.a3.

Brander, K.M. 2005. Cod recruitment is strongly affected by climate when stock biomass is low. ICES J. Mar. Sci. 62(3): 339-343. doi:10.1016/j.icesjms.2004.07.029.

Brunel, T. 2010. Age-structure-dependent recruitment: a metaanalysis applied to northeast Atlantic fish stocks. ICES J. Mar. Sci. 67(9): 1921-1930. doi:10.1093/icesjms/fsq032.

Cadigan, N.G. 2009. Sensitivity of common estimates of management parameters derived from stock-recruit relationships. Fish. Res. 96(23): 195-205. doi:10.1016/j.fishres.2008.11.003.

Cardinale, M., and Arrhenius, F. 2000. The relationship between stock and recruitment: are the assumptions valid? Mar. Ecol. Prog. Ser. 196: 305-309. doi:10.3354/meps196305.

Cushing, D.H. 1996. Towards a science of recruitment in fish populations. Ecology Institute, Oldendorf, Germany.

De Oliveira, J.A.A., Roel, B.A., and Dickey-Collas, M. 2006. Investigating the use of proxies for fecundity to improve management advice for western horse mackerel Trachurus trachurus. ICES J. Mar. Sci. 63(1): 25-35. doi:10.1016/j.icesjms.2005.07.006.

Dwyer, K.S., Morgan, M.J., Maddock Parsons, D., Brodie, W.B., and Healey, B.P. 2009. An assessment of American plaice in NAFO Div. 3LNO. Northwest Atlantic Fisheries Organization (NAFO) SCR Doc. 09/35.

González-Troncoso, D., and Fernández, C. 2009. Assessment of the cod stock in NAFO Division 3M. Northwest Atlantic Fisheries Organization (NAFO) SCR Doc 09/34.

Healey, B.P., and Mahé, J-C. 2008. Assessment of Greenland halibut (Reinhardtius hippoglossoides) in NAFO Subarea 2 and Divisions 3KLMNO. Northwest Atlantic Fisheries Organization (NAFO) SCR Doc. 08/48.

Hilborn, R., and Walters, C.J. 1992. Quantitative fisheries stock assessment: choice, dynamics and uncertainty. Chapman and Hall, New York.

Jakobsen, T., and Ajiad, A. 1999. Management implications of sexual differences in maturation and spawning mortality of Northeast Arctic cod. J. Northwest Atl. Fish. Sci. 25: 125-131. doi:10.2960/J.v25.a11.

Jørgensen, T. 1990. Long-term changes in age at sexual maturity of northeast Arctic cod (Gadus morhua L.). J. Cons. Cons. Int. Explor. Mer. 46: 235-248.

Kraus, G., Tomkiewicz, J., and Koster, F.W. 2002. Egg production of Baltic cod (Gadus morhua) in relation to variable sex ratio, maturity, and fecundity. Can. J. Fish. Aquat. Sci. 59(12): 19081920. doi:10.1139/f02-159.

Lambert, Y., Yaragina, N.A., Kraus, G., Marteinsdottir, G., and Wright, P.J. 2003. Using environmental and biological indices as proxies for egg and larval production of marine fish. J. Northwest Atl. Fish. Sci. 33: 115-159. doi:10.2960/J.v33.a7.

Lee, Y.-W., Megrey, B.A., and Macklin, S.A. 2009. Evaluating the performance of Gulf of Alaska walleye Pollock (Theragra chalcogramma) recruitment forecasting models using a Monte Carlo resampling strategy. Can. J. Fish. Aquat. Sci. 66(3): 367381. doi:10.1139/F08-203.

Mace, P.M. 1994. Relationship between common biological reference points used as thresholds and targets for fisheries management strategies. Can. J. Fish. Aquat. Sci. 51(1): 110-122. doi:10.1139/ f94-013.

Marshall, C.T. 2009. Implementing information on stock reproductive potential in fisheries management: the motivation, challenges and opportunities. In Fish reproductive biology. Implications for assessment and management. Edited by T. Jakobsen, M.J. Fogarty, B.A. Megrey, and E. Moksness. Wiley-Blackwell West Sussex, UK.

Marshall, C.T., O'Brien, L., Tomkiewicz, J., Köster, F.W., Kraus, G., Marteinsdottir, G., Morgan, M.J., Saborido-Rey, F., Blanchard, J.L., Secor, D.H., Wright, P.J., Mukhina, N.V., and Björnsson, H. 2003. Developing alternative indices of reproductive potential for use in fisheries management: case studies for stocks spanning an information gradient. J. Northwest Atl. Fish. Sci. 33: 161-190. doi:10.2960/J.v33.a8.

Marshall, C.T., Needle, C.L., Thorsen, A., Kjesbu, O.S., and Yaragina, N.A. 2006. Systematic bias in estimates of reproductive potential of an Atlantic cod (Gadus morhua) stock: implications 


\section{Pagination not final/Pagination non finale}

for stock-recruit theory and management. Can. J. Fish. Aquat. Sci. 63(5): 980-994. doi:10.1139/F05-270.

Marteinsdottir, G., and Thorarinsson, K. 1998. Improving the stockrecruitment relationships in Icelandic cod (Gadus morhua) by including age diversity of spawners. Can. J. Fish. Aquat. Sci. 55(6): 1372-1377. doi:10.1139/cjfas-55-6-1372.

Morgan, M.J. 2008. Integrating reproductive biology into scientific advice for fisheries management. J. Northwest Atl. Fish. Sci. 41: 3751. doi:10.2960/J.v41.m615.

Morgan, M.J., and Brattey, J. 2005. Effect of changes in reproductive potential on perceived productivity of three Northwest Atlantic cod (Gadus morhua) stocks. ICES J. Mar. Sci. 62(1): 65-74. doi:10.1016/j.icesjms.2004.10.003.

Morgan, M.J., and Colbourne, E.B. 1999. Variation in maturity at age and size in three populations of American plaice. ICES J. Mar. Sci. 56(5): 673-688. doi:10.1006/jmsc.1999.0487.

Morgan, M.J., Murphy, E.F., and Brattey, J. 2007. An assessment of the cod stock in NAFO Divisions 3NO. Northwest Atlantic Fisheries Organization (NAFO) SCR Doc. 07/40.

Morgan, M.J., Murua, H., Kraus, G., Lambert, Y., Marteinsdóttir, G., Marshall, C.T., O'Brien, L., and Tomkiewicz, J. 2009. The evaluation of reference points and stock productivity in the context of alternative indices of stock reproductive potential. Can. J. Fish. Aquat. Sci. 66(3): 404-414. doi:10.1139/F09-009.

Murawski, S.A., Rago, P.J., and Trippel, E.A. 2001. Impacts of demographic variation in spawning characteristics on reference points for fishery management. ICES J. Mar. Sci. 58(5): 10021014. doi:10.1006/jmsc.2001.1097.

Myers, R.A., and Barrowman, N.J. 1996. Is fish recruitment related to spawner abundance? Fish Bull. 94: 707-724.

Needle, C.L. 2002. Recruitment models: diagnosis and prognosis. Rev. Fish Biol. Fish. 11(2): 95-111. doi:10.1023/A:1015208017674.

Olsen, E.M., Heino, M., Lilly, G.R., Morgan, M.J., Brattey, J., Ernande, B., and Dieckmann, U. 2004. Maturation trends indicative of rapid evolution preceded the collapse of northern cod. Nature (London), 428(6986): 932-935. doi:10.1038/ nature02430. PMID:15118724.
Ricker, W.E. 1954. Stock and recruitment. J. Fish. Res. Board Can. 11: 559-623.

Rideout, R.M., and Morgan, M.J. 2007. Major changes in fecundity and the effect on population egg production for three species of Northwest Atlantic flatfish. J. Fish Biol. 70(6): 1759-1779. doi:10. 1111/j.1095-8649.2007.01448.x.

Rideout, R.M., and Morgan, M.J. 2009. Fecundity of cod in the northwest Atlantic. CSAS Res. Doc. 2009/020.

Rijnsdorp, A.D. 1993. Fisheries as a large-scale experiment on lifehistory evolution: disentangling phenotypic and genetic effects in changes in maturation and reproduction of North Sea plaice, Pleuronectes platessa L. Oecologia, 96(3): 391-401. doi:10.1007/ BF00317510.

Rijnsdorp, A.D. 1994. Population-regulating processes during the adult phase in flatfish. Neth. J. Sea Res. 32(2): 207-223. doi:10. 1016/0077-7579(94)90041-8.

Scott, B.E., Marteinsdottir, G., Begg, G.A., Wright, P.J., and Kjesbu, O.S. 2006. Effects of population size/age structure, condition and temporal dynamics of spawning on reproductive output in Atlantic cod (Gadus morhua). Ecol. Model. 191(3-4): 383-415. doi:10. 1016/j.ecolmodel.2005.05.015.

Shepherd, J., Pope, J.G., and Cousens, R.D. 1984. Variations in fish stocks and hypotheses concerning their links with climate. Rapp. P.-V. Reun. Cons. Int. Explor. Mer, 185: 255-267.

Sissenwine, M.P., and Shepherd, J.G. 1987. An alternative perspective on recruitment overfishing and biological reference points. Can. J. Fish. Aquat. Sci. 44(4): 913-918. doi:10.1139/f87-110.

Trippel, E.A. 1999. Estimation of stock reproductive potential: history and challenges for Canadian Atlantic gadoid stock assessments. J. Northwest Atl. Fish. Sci. 25: 61-81. doi:10.2960/J.v25.a6.

Walters, C.J., and Ludwig, D. 1981. Effects of measurement errors on the assessment of stock-recruitment relationships. Can. J. Fish. Aquat. Sci. 38(6): 704-710. doi:10.1139/f81-093.

Yoneda, M., and Wright, P.J. 2004. Temporal and spatial variation in reproductive investment of Atlantic cod Gadus morhua in the northern North Sea and Scottish west coast. Mar. Ecol. Prog. Ser. 276: 237-248. doi:10.3354/meps 276237. 